\title{
Well water level changes in Fairbanks, Alaska, due to the great Sumatra-Andaman earthquake
}

\author{
Samik Sil and Jeffrey T. Freymueller \\ University of Alaska Fairbanks, Geophysical Institute, 903 Koyukuk Drive, Fairbanks, AK 99775, USA \\ (Received June 29, 2005; Revised December 20, 2005; Accepted December 30, 2005; Online published February 17, 2006)
}

\begin{abstract}
The Mw 9.3 great Sumatra-Andaman earthquake of December 26, 2004 induced water level changes in Fairbanks, Alaska, at an epicentral distance of 10,800 km. Spike like water level changes followed by a step of water level rise were observed in at least four wells. We modeled the timing and magnitude of the water level rise using a combination of a linear trend and a step function. We calculated the misfit between the observed water level rises and our model by systematically shifting the timing of occurrence of step in water level. The minimum value of cumulative misfit suggested the timing of occurrence of steps. A previous study showed persistent water level rises in all these wells from the 2002 Denali fault earthquake and it's major aftershocks. From those observations, we developed an empirical relationship between water level changes, epicentral distances and earthquake magnitude. This relationship attributed water level changes in the wells to ground shaking by seismic waves. The estimated average water level changes due to the Sumatra earthquake using that relationship was in agreement with the observed water level changes. Thus we concluded that ground shaking in Fairbanks, induced by surface waves from the Sumatra earthquake was sufficient to change water levels.
\end{abstract}

Key words: Water level, Sumatra earthquake, Alaska.

\section{Introduction}

Seismic waves from a distant earthquake can produce water level changes in groundwater wells. Several models have been postulated to describe the processes of water level changes (Roeloffs, 1998; King et al., 1999; Brodsky et al., 2003; Montgomery and Manga, 2003). During the November 2002, Denali fault earthquake (Mw 7.9) and its aftershock sequence, we observed water level changes in 23 groundwater monitoring wells in Fairbanks, Alaska (Sil and Freymueller, manuscript in preparation). Among those 23 wells, 10 wells showed step like water level rises which persisted for a few weeks. A combination of poroelastic theory and aquifer property changes induced by ground shaking (Roeloffs, 1998) explained the observed step like water level rise. The empirical equation for water level changes due to ground shaking in those ten wells, obtained from the sequence of Denali earthquakes, suggested that the seismic waves from the December 2004, Mw 9.3 (Ms 8.9) Sumatra-Andaman earthquake (Stein and Okal, 2005) might also have measurably changed the water levels. West et al. (2005) showed that seismicity was triggered at Mount Wrangell volcano, Alaska, at the onset of the arrival of surface waves from Sumatra. These two facts led us to investigate the changes in groundwater level in Fairbanks after the Sumatra-Andaman earthquake.

Copyright (c) The Society of Geomagnetism and Earth, Planetary and Space Sciences (SGEPSS); The Seismological Society of Japan; The Volcanological Society of Japan; The Geodetic Society of Japan; The Japanese Society for Planetary Sciences; TERRAPUB.

\section{Well Settings, Instrument}

The 10 ground water wells we studied were all drilled into Quaternary Chena alluvial deposits. The aquifer system is unconsolidated and is considered as confined because of the presence of a permafrost layer and seasonal frost layer during winter [Personal communication with Edward Plumb, Hydrologist, National Weather Service]. The area of investigation falls in the Tanana Valley area of Alaska, which is covered by thick deposits of alluvium and loess. The whole valley is surrounded by an upland consisting of fractured bedrock metamorphic schist (Anderson, 1970) of the Yukon-Tanana terrane. The well locations are plotted in Fig. 1. The wells were monitored by the USGS water Resource Division office in Fairbanks. Water level data are collected at an interval of fifteen minutes in all the wells. Submersible pressure transducers were used to measure the water level data with an accuracy of $0.3 \mathrm{~mm}$.

\section{Background Work and Present Observations}

While investigating the water level changes in those same 10 USGS wells due to the 2002 Denali fault earthquake, we obtained an empirical relationship between water level rise due to ground shaking and distance from the point of maximum slip on the Denali fault (Fig. 2):

$$
\log (w)=-1.8032 * \log (d)+k
$$

Where $(w)$ is the water level rise, $(d)$ is the distance of the well from the point of maximum slip on the fault and $(k)$ is a constant. The constant $(k)$ can be written as a function of the magnitude of the earthquake (Roeloffs, 1998). We studied the water level rises from several local earthquakes 

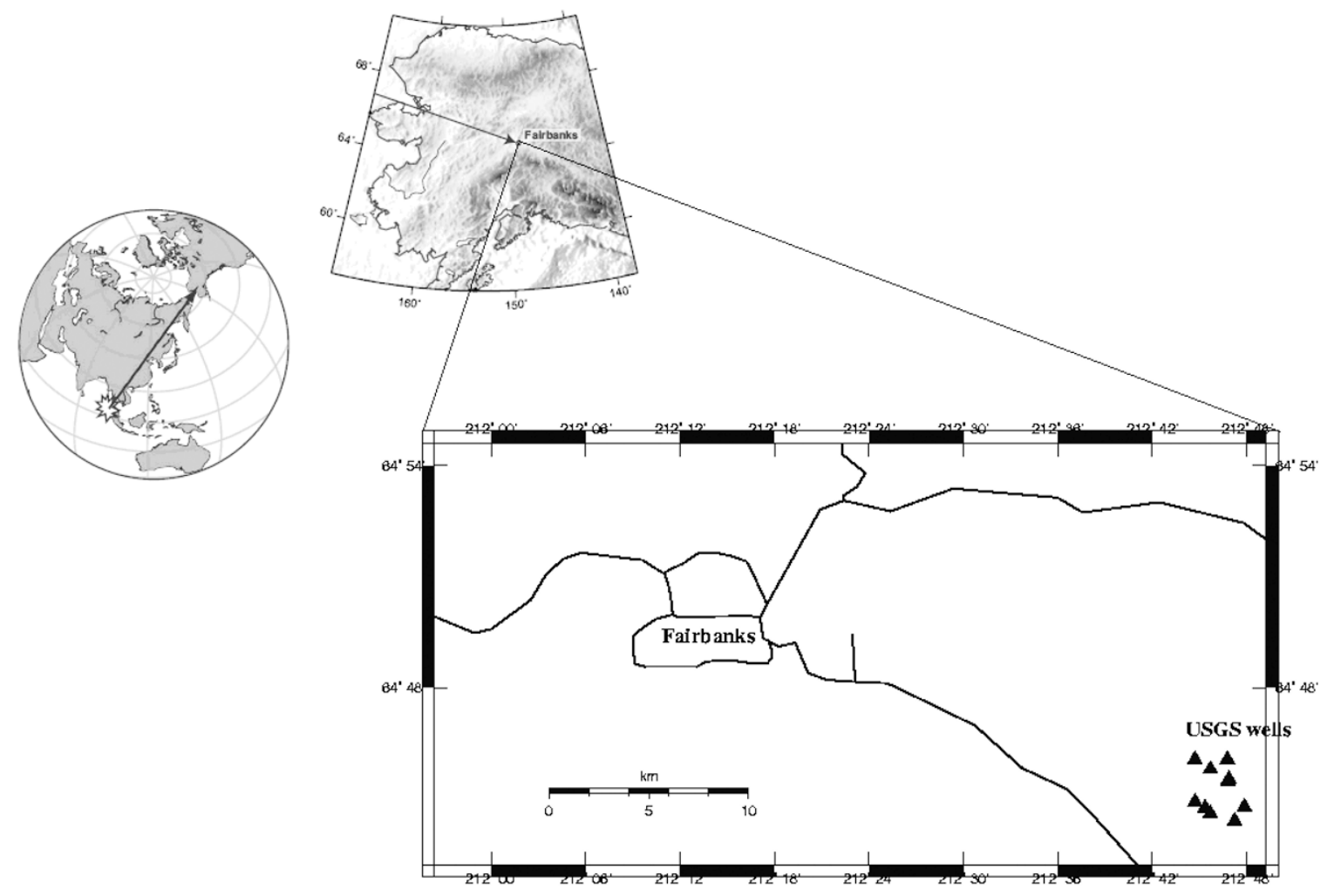

Fig. 1. Location of the studied USGS wells and wave path from Sumatra to Fairbanks, Alaska, after the earthquake. The wave path was mostly continental (West et al., 2005).

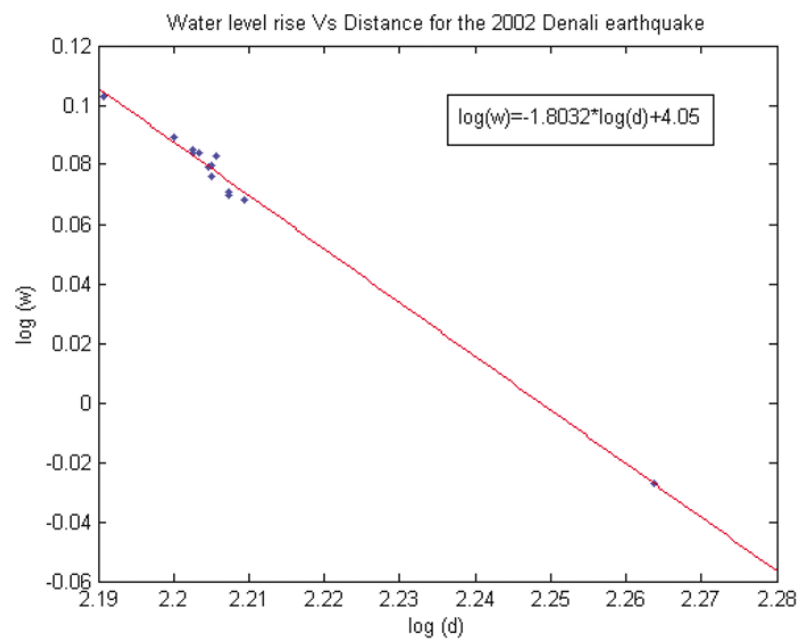

Fig. 2. Log water level rise in the same wells as a function of log distance from the maximum slip point on the Denali fault, after the 2002 Denali earthquake. Some of the wells were omitted in the present study, because of the very low temporal resolution of the data. The relationship suggests that water level rise is inversely proportional to the square root of the distance.

and got the empirical relation:

$$
k=M-4.45
$$

Where $(M)$ is the magnitude of the earthquake (Ms, where the data are available). Substituting Eq. (1) into Eq. (1), we obtained an empirical relationship between $(w),(d)$ and $(M)$ :

$$
\log (w)+1.8032 * \log (d)=M-4.45
$$

Similar empirical relations were obtained for the wells in Japan and California after local and distant earthquakes (Roeloffs, 1998; Matsumoto et al., 2003).

Equation (3) suggests an expected average water level rise of $\sim 1.5 \mathrm{~mm}$ in the studied wells due to the SumatraAndaman earthquake. Though the resolution of water level measuring system is high enough to determine a water level change of this magnitude, the inherent noise in the data make it difficult to visualize the changes from raw water level data. We corrected the water level data for atmospheric and tidal effects. No correlation with precipitation was found, probably because precipitation in winter rmains frozen at the surface. Figure 3 shows the uncorrected and corrected water level data for more than one month for the DSAP 6 well. During correction, we obtained an average Skempton's coefficient $(B)$ value of 0.02 . The low $B$ value may indicate that the wells were not perfectly confined during the winter of 2004.

Among the 10 wells, coseismic water level changes were distinctly identified in all of the wells. In most wells, we observed a distinct spike like water level changes followed by a step like water level rise (Fig. 3). The water level rise persisted for more than 2-3 days in all 10 wells. Since the spike like water level changes were distinct, the timing of the occurrence of the spike was determined easily; it coincided with the arrival of first seismic waves from Sumatra. But because of the presence of inherent noises in the water level, the timing of the step was more difficult to identify.

To identify the timing of steps, we assumed that over a short period including the earthquake, the water level could be modeled using a combination of a linear and Heaviside 


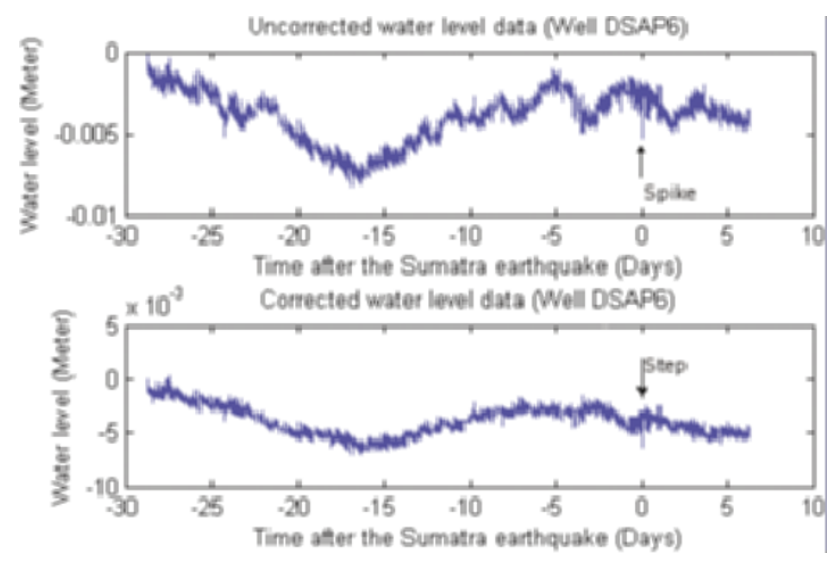

Fig. 3. More than one month of water level data from the well DSAP6 (December 2004). Uncorrected water levels are shown in the top panel. A spike like change during the earthquake is visible even in the uncorrected data. In the bottom panel atmospheric and tidal force corrected water level data are shown. Though small in magnitude, a step is quite clear in the corrected data.
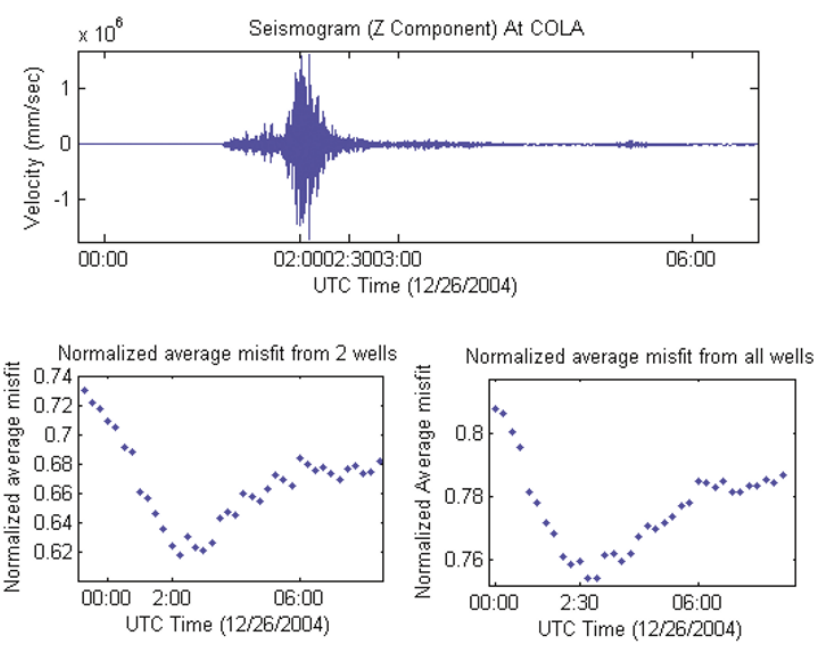

Fig. 4. Misfit between observed data and our model, estimated by varying the timing of step function change in each well. Bottom left is the combined misfit from well DSAP4 and USP5 (where magnitude of the steps are maximum), which suggests step occurred at 02:00 UTC time of 12/26/2004 (minimum error). Bottom right is the cumulative normalized misfit from all the wells, suggesting in most of the wells, step occurred at 02:30 UTC time of the same day. In the top, seismogram (vertical) from GSN station COLA. In between time 2:00 and 2:30 the largest surface wave from Sumatra was passing through Alaska.

(step) function of the form:

$$
w(t)=A+B * t+C * H\left(t-t_{o}\right)
$$

Where $w(t)$ is the observed water level at any time $t, A$ and $B$ are constants, $t_{o}$ is the time of occurrence of the step in the water level, $C$ is the magnitude of water level rise and $H$ is the Heaviside function. Four of the wells showed strong variability in water level or high noise levels both before and after the earthquake, and were not useful in constraining the timing of the steps. For each of the 6 remaining wells we selected 5 days of water level data (2.5 days before and 2.5 days after the earthquake). We fit the data from each well using Eq. (4), and calculated the misfit by gradually changing $t_{o}$ from $t$ ( 1 st day, 1 st data point) to

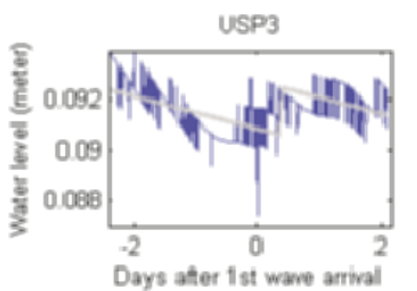

DSAP6

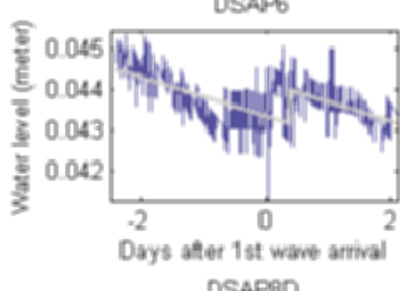

DSAPBD

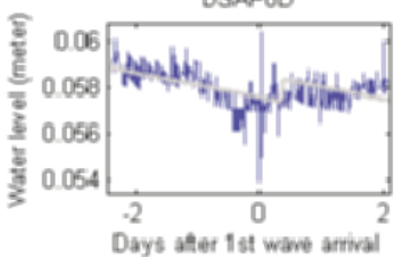

Days ater fit wave arrival

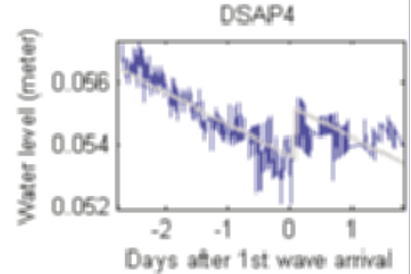

DSAP7

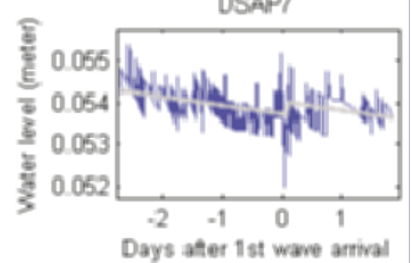

USPS

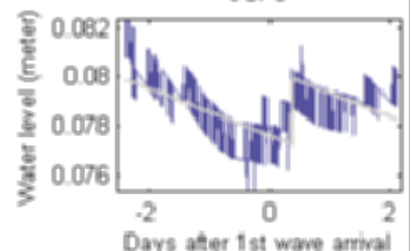

Days ater 1 st wave arrival
Fig. 5. 5 days of water level data from 6 wells. The best fit model is also shown in the same plot (smooth gray line). Offsets are visible in all the 10 wells. We showed those wells, where pre and post earthquake water levels can be fitted with straight lines.

$t$ (5th day, last data point). The misfit was then normalized by the misfit to a model with no step (linear trend only). This makes the fractional improvement in misfit relative to a model with no step obvious. Misfit in models with a step was generally $25-40 \%$ lower than its models with no step. The total cumulative error $(E)$ is:

$$
E=(1 / i) *_{s}(t)_{i} / \max \left(s(t)_{i}\right)
$$

Where $s(t)_{i}$ was the misfit of ith well ( $i=1$ to 6 , for 6 wells). Because of the normalization, misfit from each well had equal weight. We assumed the minimum $E$ corresponded to the timing of the offset in the water level. In Fig. 4, we plot $E$ as a function of time. We also plot the cumulative misfit for the well DSAP4 and USP5 where the water level changes were largest. In the same figure, the vertical component seismogram from GSN station COLA is shown. A step like increase in water level occurred in between UTC time 02:00 to 02:30 of December 26th, 2004, during the passage of largest surface waves from Sumatra. In Fig. 5 we plot the 5 days of water level data along with the best fit step model from least squares analysis, using Eq. (1). The water level rise obtained from the 6 wells varied between 0.3 and $2.7 \mathrm{~mm}$, with an average of $1.4 \mathrm{~mm}$.

\section{Discussions and Conclusions}

We observed spike like changes in water level in several wells (Figs. 3 and 5). Since the magnitudes of the spikes were several times larger than the normal fluctuations of water level and they occurred around the time of first $P$ and $S$ wave arrival from Sumatra, we suspect that the spikes were induced by seismic waves. Because of the low temporal resolution of the data, further analysis of the spike could not be made. Step like water level changes occurred 
in 10 wells during the passage of largest surface waves (in between UTC time 02:00 to 02:30). More precise estimation of the timing of the step could not be made because of the low temporal resolution of the data. The magnitude of steps varied between $<1$ to $2.7 \mathrm{~mm}$ with an average of $1.4 \mathrm{~mm}$, which is compatible with the predicted water level rise using empirical Eq. (1). The step-like changes might be explained by one of several existing models of far-field coseismic pore pressure changes including mobilization of gas bubble, (Roeloffs, 1998), shaking induced dilatancy (Bower and Heaton, 1978), fracture of an impermeable fault (King et al., 1999) and fracture clearing (Brodsky et al., 2003). The water level in the Fairbanks wells roughly followed empirical Eq. (1), (inverse square relation between $w$ and $d$ ), which suggests that dynamic strain due to surface waves might be the cause of water level changes.

West et al. (2005) showed that dynamic strains due to surface waves from the Sumatra earthquake triggered seismicity at Mount Wrangell, Alaska. They suggested that a pressure increment induced by the surface waves could squeeze fluid from interconnected pore space into the nearby fault system and reduced the effective fault friction. Persistent steam emission of Mount Wrangell helped to establish this fluid pumping model. Our observation of water level increase in the wells provides additional support for this phenomenon.

Acknowledgments. We would like to thank Heather R. Best (USGS, Fairbanks) and Dr. Martha Shulski (IARC, UAF) for providing us the water level data and atmospheric pressure data respectively. We are grateful to Dr. Emily Brodsky and the anonymous reviewer for their valuable comments and help, which greatly improve the paper.

\section{References}

Anderson, G. S., Hydrological reconnaissance of the Tanana Basin, central Alaska, U.S. Geological Survey Hydrological Investigation Atlas, HA319, 1970.

Bower, D. R. and K. C. Heaton, Response of an aquifer near Ottawa to tidal forcing and the Alaskan earthquake of 1964, Can. J. Earth Sci., 15, 331-340, 1978

Brodsky, E., E. Roeloffs, D. Woodcock, I. Gall, and M. Manga, A mechanism for sustained groundwater pressure changes induced by distant earthquake, J. Geophys. Res., 108, 2390, 2003.

King, C.-Y., S. Azuma, G. Igarashi, M. Ohno, H. Saito, and H. Wakita, Earthquake-related water-level changes at 16 closely clustered wells in Tono, central Japan, J. Geophys. Res., 104, 13,073-13,082, 1999.

Matsumoto, N., G. Kitagawa, and E. A. Roeloffs, Hydrological response to earthquakes in the Haibara well, central Japan-I. Groundwater level changes revealed using state space decomposition of atmospheric pressure, rainfall and tidal responses, Geophys. J. Int., 155, 885-898, 2003.

Montgomery, D. and M. Manga, Streamflow and water well responses to earthquakes, Science, 300, 2047-2049, 2003.

Roeloffs, E., Persistent water level changes in a well near Parkfield, California, due to local and distant earthquakes, J. Geophys. Res., 103, 869889, 1998.

Stein, S. and E. Okal, Speed and size of the Sumatra earthquake, Nature, 434, 581-582, 2005.

West, M., J. Sanchez, and S. McNutt, Periodically-triggered seismicity at Mt. Wrangell volcano following the Sumatra earthquake, Science, 308, 1144-1146, 2005.

S. Sil (e-mail: ftss@uaf.edu) and J. T. Freymueller 